\title{
The Patterns of Dental Caries Influence on the Children's Quality of Life Aged 3-5 Years Based on the Socioeconomic Characteristics
}

\author{
Taufan Bramantoro ${ }^{1, ~ *, ~ Y a y i ~ S u r y o ~ P r a b a n d a r i ~}{ }^{2}$, Djauhar Ismail ${ }^{3}$, Udijanto Tedjosasongko ${ }^{4}$ \\ ${ }^{1}$ Department of Dental Public Health, Faculty of Dentistry, Airlangga University, Surabaya, Indonesia \\ ${ }^{2}$ Department of Public Health, Faculty of Medicine, Gadjah Mada University, Yogyakarta, Indonesia \\ ${ }^{3}$ Department of Pediatrics, Faculty of Medicine, Gadjah Mada University, Yogyakarta, Indonesia \\ ${ }^{4}$ Department of Pediatric Dentistry, Faculty of Dentistry, Airlangga University, Surabaya, Indonesia
}

Email address:

tbramantoro@gmail.com (T. Bramantoro)

\section{To cite this article:}

Taufan Bramantoro, Yayi Suryo Prabandari, Djauhar Ismail, Udijanto Tedjosasongko. The Patterns of Dental Caries Influence on the Children's Quality of Life Aged 3-5 Years Based on the Socioeconomic Characteristics. Science Journal of Public Health.

Vol. 3, No. 6, 2015, pp. 830-835. doi: 10.11648/j.sjph.20150306.16

\begin{abstract}
The objective of this research was to analyze the patterns of dental caries influence on the children's quality of life aged 3-5 years based on the socioeconomic characteristics of their mother in Mojokerto Indonesia. This research can be considered as an observational analytic. This research was conducted in Puskesmas Wates Mojokerto and involved children aged 3-5 years as well as their mother. In total, this research involved 309 children and their mothers. Data obtained was related to the number of deciduous tooth caries cases and the assessment of children's quality of life obtained from their mothers, that have been tested for their validity and reliability. In all of the groups of the socioeconomic characteristics, it is known that the number of dental caries cases found generally had considerable effects on the children's quality of life. Next, based on the analysis of the influence followed with multigroup analysis aimed to know the significance of the difference between the coefficient values of each group of socioeconomic characteristics, it is also known that among those three groups there was a significant coefficient value in the socioeconomic characteristic group of children living at the same house with their mother. It can be concluded that in the group of mothers who have more than two children, dental caries has significantly greater effect on the children's quality of life than that in the group of mothers who have fewer than or equal to two children.
\end{abstract}

Keywords: Children Dental Caries, Children Quality of Life, Socioeconomics Factors

\section{Introduction}

Efforts to improve the quality of oral health should be done as early as possible since oral health in toddlers and preschool children becomes an important factor for the next tooth growth and can also affect the children's ability to speak and digest food [1]. Various prevention efforts and dental caries treatments have continually been developed in many countries. However, although these prevention efforts and dental caries treatments have shown a positive and dynamic movement, the incidence of dental caries is still higher, particularly in developing countries. In several researches on the incidence of dental caries in several countries in the world, especially developing countries, dental caries even can still be described as common dental health problem found at an early age children and preschool children between the ages of 1-6 years old [2].

In preliminary observation in the area of Puskesmas (Public Health Center) Wates Mojokerto, moreover, the results show that the incidence of early childhood dental caries was still high although health promotion activities have been carried out on a regular program. Based on data about child dental caries incidence in the area of Puskesmas Wates in 2013, it is known that the incidence of dental caries was high up above $70 \%$.

It is because there is a common misperception owned by parents in the community about deciduous teeth. They always believe that the presence of deciduous teeth is only temporary and will then be replaced by permanent ones, so the presence of deciduous teeth is not considered to be important [3]. This misperception, as a result, has made dental caries or cavities in early childhood often overlooked by their parents. 
Thus, prevention and treatment efforts concerned with dental caries problems in children require further and special attention. It is because dental caries problem in children not only have potential to evolve, but also have a significant impact on the children's quality of life associated with disorders of masticatory system and child daily activities [4].

However, the planning efforts of dental caries prevention and treatment are not only focused on its clinical impact, but must also be focused on the assessment and measurement of its impact on the quality of life, especially related to dental health problems. Oral health problems that are chronic, along with their symptom development and their effects in line with style and lifestyle, demand the need for assessment method for their chronic impact, both socially and psychologically, instead of their clinical indicators [5].

Unfortunately, prevention efforts that must be conducted as early as possible still have not been followed by rapid researches focused on the assessment of the children's quality of life, specifically under the age of 5 years, associated with their oral health condition. It is because the number of researches focusing on the impact of dental health problems during early childhood on the children's quality of life is still considered limited compared to the development of the same researches focusing on the impact of dental health problems during adulthood [4].

Based on the above discussion about the influences of the norms and culture of the society towards quality of life assessment, it can be assumed that there is a need for a research on quality of life assessment of children with Indonesian culture background by observing group of toddlers or children under the age of 6 years. Quality of life assessment can describe socio demographics and cultural background of people as well as various special characteristics of a community, especially related to age group. This is related to the nature of oral health which has different sensitivity among age groups [6], [7].

To get oral health status assessment comprehensively, observation must be conducted individually or in groups, not only involving the existence of diseases, but also the status of physical function, psychological function, social function, and satisfaction with health. In other words, it can be assumed that the aspects of quality of life are important in planning and assessment processes related to the effectiveness of oral health program. Quality of life assessment can provide a powerful additional dimension in the planning and evaluation of health promotion programs. Thus, the assessment must be associated with the consideration of efforts made by a person in accepting the delivery of oral health programs in order to improve the quality of his dental and oral health [5], [8], [9].

Unlike the number of researches on factors associated with the incidence of dental caries in children, the number of researches on factors affecting the children's quality of life aged 3-5 years related to dental health is still not high, especially in Indonesia. Based on the results of some researches on factors affecting the assessment of the children's quality of life, it is also known that the development of measuring instruments related to children's quality of life, especially in the group of toddlers or children at early ages is still low [10], [11].

There are several researches which can then become references for studying factors affecting the children's quality of life although there are not many researches focusing on children aged 3-5 years. Based on the results of those researches, it is known that there are not only clinical factors, but there are also potential influences of socioeconomic condition on the children's quality of life. The results of those researches also show a comprehensive analysis related to child dental health problems and their non-clinical factor role on the children's quality of life [12], [13], [14], [15].

As the use of quality of life assessment to determine the priority target of dental health promotion program, this research is aimed to analyze the patterns of dental caries influence on the children's quality of life aged 3-5 years based on the socioeconomic characteristics of their mothers in Mojokerto Indonesia by using multigroup analysis compared to the coefficient values of the effects of each socioeconomic characteristic group.

\section{Materials and Method}

This research is an observational analytic research using cross-sectional study design. This research was conducted in Puskesmas, Wates Mojokerto from January 2015 to March 2015. This research involved children aged 3-5 years who had dental caries and also were students in kindergarten and early childhood program in Puskesmas Wates Mojokerto as well as their mothers. Thus, the total of the participants in this research was 309 children and their mothers.

Moreover, there are several criteria used in this research. First, monthly household consumption expenditure, which is the total amount of household consumption expenditure on goods and services to meet their needs calculated every month, was used to categorize the group of participants. Thus, there were two groups based on the national average of monthly household consumption expenditure according to BPS (in 2013 about Rp. 740. 250,-), namely the group of families with monthly household consumption expenditure less or equal to Rp. $1.485 .000(\leq 2 \times$ national average of household consumption expenditure per month) and the group of families with monthly household consumption expenditure more than Rp. 1.485 .000 ( $>2 \mathrm{x}$ national average of household consumption expenditure per month).

Second, the formal education level of mothers was also used as one of criteria. Thus, there were two groups, namely the group of mothers with formal education level less or nine years old ( $\leq 9$ years old) and the group of mothers with formal education level more than nine years old ( $>9$ years). Third, the number of children who live at the same house with their parents also became one of criteria. Therefore, there were two groups, namely the group of mothers with fewer than or equal to two children $(\leq 2$ children) and the group of mothers with more than two children ( $>2$ children).

Moreover, the number of dental caries in children refers to 
the total number dental caries experience in children. Assessment of the children's quality of life was based on their mother's perception related to how big the disruption of their children's quality of life and normal activities was as a result of dental health. The assessment was in the form of a mean value. The assessment involved three aspects, namely physical aspects, functional aspects, and psychological aspects. Thus, questionnaire used to measure children's quality of life was adapted from the synthesis of some measuring instruments of the children's quality of life that had been developed previously, namely ECOHIS, SOHO-5, and OHRQoL-C5 [11], [16], [17].

In addition, instrument used to measure the influence of dental health problems of children aged 3-5 years on children's quality of life was tested with a series of validity and reliability. The assessments for these tests involved the perception of parents or, especially mothers who have a major role in early childhood care as an early social environment for their children. Besides that, parents are assumed to be able to recognize and understand the problems of early childhood, especially associated with pain, sleep disorders, and discomfort as a result of early childhood dental caries. This condition is related to the psychological development of children aged 3-5 years who are still not able to interpret questions used to measure children's quality of life. Thus, parents can be considered as a good source of information to get an valid assessment of children's quality of life [11], [10], [18].

Furthermore, there were several stages in making questionnaire used as an instrument measuring the children's quality of life aged 3-5 years, which also have usually been used in several other countries [11], [16], [19]. However, the questionnaire was still made based on the characteristics of Indonesian society. The first stage was conducting focus group discussion to find out and get construction theme that would be used in the instrument to measure the children's quality of life associated with their early childhood dental caries condition. This focus group discussion was conducted on a group of mothers, ie mothers with children who have dental caries. In the group, there were seven respondents determined by purposive sampling technique. This focus group discussion was also conducted based on the construction of the instrument that had been used and found in references.

The second stage was drafting the question items used as measuring instrument. The draft of the question items used as measuring instrument then was tested for the feasibility of its content and structure. This feasibility test was conducted by doing interviews or discussions with dentists, pediatric dentists, and dentists in the field of public health to see comprehensiveness, relevance ranking, and clarity. The interviews and discussions were followed with ten respondents determined by purposive sampling technique. The question draft that had been tested by dental health experts was then tested again by the mothers who have children aged 3-5 years with dental caries. This feasibility test with those mothers was aimed to see comprehensiveness, relevance ranking, clarity, addition, understanding, and readability. Afterwards, the draft was tested for its validity and reliability.

In the third stage, the validity and reliability tests were conducted to obtain the final draft of the question item arrangement used as an instrument for measuring the influence of the dental health of children aged 3-5 years on children's quality of life. Based on the results of those tests, it is known that this measuring instrument for the children's quality of life aged 3-5 years had a Cronbach' s Alpha value of 0.867 and validity value greater than the critical value of two-way correlation coefficient (r) in 55 samples of people, equal to 0.261 . It means that those question items were reliable internally and valid.

In the fourth stage, external reliability test was conducted by comparing respondents at two-time assessment, which means the first answer assessment was conducted three weeks before the second one. Based on the test results, it is then known that there was no significant difference between the first answer assessment and the second one with a value of $\mathrm{p}>0.05$.

Moreover, there were several questions delivered as an instrument for measuring the influence of the dental health of children aged 3-5 years on children's quality of life. Those questions had successfully been tested for their validity and reliability. Those questions were as follow: "Did your child ever feel fussy / anxious?", "Did your child ever feel unwilling or uncomfortable to eat and drink?", "Is your child ever absent from school?", "Did your child never sleep or feel difficulty in sleeping?". The answers of those questions were "Ever" and "Never". The answer "Ever" was given a score of 1 , while "Never" was given a score of 2 .

Finally, before starting to fill out the questionnaire and dental examination of their children, those mothers were given informed consent which had to be signed by them as their approval to participate as research samples. Next, this research was approved by Medical and health research ethics committee of Medicine Faculty of Gadjah Mada University.

Statistical analysis were conducted using EXCEL by Microsoft and XLSTAT software by Addinsoft. Frequency and mean tables were generated for various categorical and continuous variables. Multigroup analysis were used for comparing to the coefficient values of the effects of each socioeconomic characteristic groups.

\section{Results}

Table 1. Distribution of Child Dental Caries Impact on Quality of life.

\begin{tabular}{lll}
\hline \multirow{2}{*}{ Quality of life Impacts } & \multicolumn{2}{l}{ Frequency of Answer } \\
\cline { 2 - 3 } & Ever & Never \\
\hline $\begin{array}{l}\text { Did your child ever feel fussy / } \\
\text { anxious? }\end{array}$ & $159(51.5 \%)$ & $150(48.5 \%)$ \\
$\begin{array}{l}\text { Did your child ever feel unwilling or } \\
\text { uncomfortable to eat and drink? }\end{array}$ & $130(42.1 \%)$ & $179(57.9 \%)$ \\
$\begin{array}{l}\text { Is your child ever absent from school? } \\
\begin{array}{l}\text { Did your child never sleep or feel } \\
\text { difficulty in sleeping? }\end{array}\end{array}$ & $73(23.6 \%)$ & $236(76.4 \%)$ \\
\hline
\end{tabular}


Based on the data obtained in this research, it can be seen that the distribution of sex between boys and girls was normal, namely 159 boys $(51.5 \%)$ and 150 girls (48.5\%). Furthermore, the data obtained also show that the average number of teeth suffering from dental caries in those children was seven $(7.848 ; \mathrm{SD}=5.032)$. It is also known that the average of the children's quality of life was high enough or close to the maximum value $(1.624 ; \mathrm{SD}=0.338)$.

Based on Table 1, it can be said that children who become fussy or anxious have poor quality of life as a result of suffering dental caries.

Table 2. Description and Distribution of Social and Economic Characteristics of the Mothers.

\begin{tabular}{|c|c|c|c|c|c|c|}
\hline \multirow{2}{*}{ Social and Economic Variable } & \multirow{2}{*}{ Group } & \multirow{2}{*}{ Frequency } & \multicolumn{2}{|c|}{ Dental Caries } & \multicolumn{2}{|c|}{ Quality of Life } \\
\hline & & & Mean & SD & Mean & SD \\
\hline \multirow{2}{*}{ Education Level of the Mothers } & $\leq 9$ years & $35(11.3 \%)$ & 8,571 & 4.578 & 1.557 & 0.364 \\
\hline & $>9$ years & $274(88.7 \%)$ & 7.756 & 5.087 & 1.632 & 0.334 \\
\hline \multirow{2}{*}{ Family Expenditure per month } & $\leq 1.485 .000$ & $105(34 \%)$ & 8.314 & 4.841 & 1.593 & 0.328 \\
\hline & $>1.485 .000$ & $204(66 \%)$ & 7.608 & 5.122 & 1.639 & 0.343 \\
\hline $\begin{array}{l}\text { Number of children living at the } \\
\text { same house with their parents }\end{array}$ & $>2$ children & $57(18.4 \%)$ & 8.842 & 5.421 & 1.583 & 0.351 \\
\hline
\end{tabular}

Based on Table 2, it can be seen that the average number of dental caries in children aged 3-5 years in the group of mothers with education level less than or equal to 9 years was higher than that in the group of mothers with education level more than 9 years. It is also known that the children's quality of life in the group of mothers with education level less than or equal to 9 years was lower than that in the group of mothers with education level more than 9 years. The similar pattern was also found in the group of children whose family expenditure per month less than $\leq 1.485 .000$ compared to that in the group of children whose family expenditure per month more than $>1.485 .000$. Similarly, it can be known that the children's quality of life in the group of children who have more than two siblings was lower than that in the group of children who have no or two siblings.

Table 3. Comparison of Influence Coefficients of the Number of Child Dental Caries on the Children's quality of life based on Social and Economic Characteristics of the Mothers.

\begin{tabular}{lllll}
\hline Social and Economic Variable & Group & R square & Influence Coefficient & Multigroup Test Significance \\
\hline \multirow{2}{*}{ Education Level of the Mothers } & $\leq 9$ years & 0.527 & -0.726 & 0.204 \\
& $>9$ years & 0.671 & -0.819 & 0.652 \\
Family Expenditure per month & $\leq 1.485 .000$ & 0.627 & -0.792 & 0.020 \\
Number of children living at the same & $>1.485 .000$ & 0.663 & -0.814 & 0.912 \\
house with their parents & $>2$ children & 0.831 & -0.910 & -0.781 \\
\hline
\end{tabular}

Table 3 shows that all the groups of socioeconomic characteristics, it is generally found that the number of dental caries had a considerable effect on the children's quality of life aged 3-5 years. It can be seen from the data that more than $50 \%$ of the dynamics occurred on the children's quality of life aged 3-5 years can be explained by the number of dental caries. The influence coefficient obtained was greater than 0.7 . Thus, it can be said that there is opposite relation between the number of children's dental and the children's quality of life. In other words, the higher number of children's dental caries obtained is, the lower quality of life is.

Moreover, based on the results of multigroup analysis, it is known that there were significant differences of the influence coefficient values among the groups of socioeconomic characteristics related to the number of children living at the same house with their parents $(p=0.020 ; p \leq 0.05)$. It can be seen that the influence coefficient value in the group of mothers with more than two children was greater than that in the group of mothers with fewer than or equal to two children. It means that the condition of mothers with more than two children, dental caries has significantly greater effect on the children's quality of life compared to the condition of those with fewer than or equal to 2 children.

\section{Discussion}

The existence of dental and oral tissues in complex cranofacial system strengthens the influence of dental and oral health on the quality of someone's life. Cranofacial system has an important role in social interaction and nutrition for humans. For instance, one's abilities to speak, smile, speak, express feelings, recognize smell, taste food, chew, and swallow are important functions in human life. Thus, dental and oral health problems will give negative impacts on those functions, and will also affect the quality of someone's life [20].

Moreover, early childhood caries can cause disruptions or negative impacts on the children's quality of life. For example, dental caries can cause painful disorders, discomfort in mouth, chewing disorders, speech disorders, discomfort in playing or learning, and sleeping disorders. These disorders can then lead to pressure or stress in children, especially requiring medication. Social and psychological 
disorders occurred in early childhood will also have a negative impact on the decreasing of the children's quality of life [21], [20]. It is because dental caries can trigger pain caused by inflammatory processes in dental caries, limited function of teeth, and psychological discomfort [10].

In a research conducted by researchers at Mojosari, East Java, it is also known that there was a significant relation between the number of dental caries in children aged 4-5 years and the children's daily activities, such as eating, learning, and playing [23].

Similarly, in another study it is known that there were several common problems associated with the influences of child dental caries on children's quality of life, such as their self-empowerment to learn and play, their ability to chew food well, their ability to drink hot or cold drinks, their sociability, and their sleeping activity. In other words, it can be said that the children's quality of life is a factor often affected by dental caries. Severe early childhood caries even can also become a potential disruption for their pronunciation ability and their growth [10], [22], [4], [24].

In addition, the results of some researches show that a comprehensive analysis about the role of children's behavior related to dental health towards $\mathfrak{t}$ children's quality of life is needed. Similarly, the researcher also found that dental caries is not the dominant factor affecting the children's quality of life, but there are also some influencing non-clinical factors [12], [13], [14], [15].

For instance, based on the result of this research, it is known that the number of children who live in the same house with their parents had significant impacts of dental caries on children's quality of life. It can be seen that the coefficient value of dental caries effect on the children's quality of life in the group of mothers with more than two children was greater than that in the group of mother with fewer than or equal to two children. It indicates that in families with many children, the number of dental caries becomes a dominant factor significantly affecting the children's quality of life. In other words, it can be said that children who have early childhood caries and also have many siblings tend to have worse quality of life than children who do not have many siblings or only have one sibling.

Therefore, it can be said that family environment will give significant effect to the growth and development of children in the family. In other words, a family will give an exclusive and significant influence on their children early in life. Based on the results of the analysis in this research, it can be said that the patterns of influence coefficients of the groups of characteristics, especially concerned with the number of children who live at home, can portray how their mothers share their attention and focus to their children. It means that children in a nuclear family or living with their parents with no or few siblings will get more focus and attention from parents, particularly relating to their dental health condition. This condition then gives an influence on the children's quality of life. In short, it can be said that the more the number of children in families, the more competitive the children have to get attention from their parents. As a result, the quality of care and attention from the mothers to the children will be reduced [4], [14], [15], [25].

\section{Conclusion}

It can be concluded that in the group of mothers who have more than two children, dental caries has significantly greater effect on the children's quality of life than that in the group of mothers who have fewer than or equal to two children. Puskesmas Wates Mojokerto as the spearhead of the Ministry of Health is expected to use the results of this research to improve the effectiveness of dental health promotion programs for children. Puskesmas Wates is also expected to give more attention to families with many children related to dental health promotion programs since the results of this research show that the number of children who live at home with parents can give significant influence on the children's quality of life.

\section{References}

[1] Ismail. AI. (2003). Determinants of Health in Children and the Problem of Early Childhood Caries. Pediatric Dentistry. 25: 4. 328-333.

[2] Bagramian. RA., Garcia-godoy. F., Volpe. AF. (2009). The global increase in dental caries. A pending public health crisis. American Journal of Dentistry. 21 (1): 3-8.

[3] Mouradian, WE.(2001).The Face of a Child: Children's Oral Health and Dental Education. Journal of Dental Education, 65 (9): 821-831.

[4] Abanto. J., Carvalho. TS., Fausto. MM., Marcia. TW., Marcelo. B., and Daniela. PR. (2011). Impact of oral diseases and disorders on oral health-related quality of life of preschool children. Community Dent Oral Epidemiol. 39: 105-114.

[5] Petersen. PE., and Kwan. S. (2004). Evaluation of community-based oral health promotion and oral disease prevention - WHO recommendations for improved evidence in public health practice. Community Dental Health 21 (Supplement): 319-329.

[6] John. MT., Hujoel. P., Miglioretti. DL., LeResche. K., Koepsell. TD., and Micheelis. W. (2004). Dimensions of Oral-healthrelated Quality of Life. Journal Dental Research. 83: 956.

[7] Al Shamrany. M. (2006). Oral health-related quality of life: a broader perspective. Eastern Mediterranean Health Journal. 12(6): 894-901.

[8] Hobdell, M., Petersen, PE., Clarkson, J., and Johnson, N. (2003). Global goals for oral health 2020. International Dental Journal, 53: 285-288.

[9] Sischo. L., and Broder. HL. (2011). Oral Health-related Quality of Life: What. Why. How. and Future Implications. J Dent Res. 90 (11): 1264-1270.

[10] Filstrup. SL., Briskie. D., Marcio da. F., Lawrence. L., Wandera. A., and Inglehart. MR. (2003). Early Childhood Caries and Quality of Life: Child and Parent Perspectives. Pediatric Dentistry. 25 (5): 431-440. 
[11] Pahel. BT., Rozier. RG., and Slade. GD. (2007). Parental perceptions of children's oral health: The Early Childhood Oral Health Impact Scale (ECOHIS). Health and Quality of Life Outcomes. 5: 6.

[12] Locker. D. (2007). Disparities in oral health-related quality of life in a population of Canadian children. Community Dent Oral Epidemiol. 35: 348-56.

[13] Piovesan. C., Antunes. JLF., Guedes. RS., Ardenghi. TM. (2010). Impact of socioeconomic and clinical factors on child oral health-related quality of life (COHRQoL). Qual Life Res. 19: 1359-1366.

[14] Paula. JS., Leite. ICG., Almeida. AB., Glaucia. MBA., Pereira. AC., and Mialhe. FL. (2012). The influence of oral health conditions. socioeconomic status and home environment factors on schoolchildren's self-perception of quality of life. Health and Quality of Life Outcomes. 10: 6 . http://www.hqlo.com/content/10/1/6.

[15] Paula. JS., Leite. ICG., Almeida. AB., Ambrosano. GMB., and Mialhe. FL. (2013). The impact of socioenvironmental characteristics on domains of oral health-related quality of life in Brazilian schoolchildren. BMC Oral Health. 13:10. http://www.biomedcentral.com/1472-6831/13/10.

[16] Tsakos. G., Blair. YI., Yusuf. H., Wright. W., Watt. RG., and Macpherson. LMD. (2012). Developing a new self-reported scale of oral health outcomes for 5-year-old children (SOHO5). Health and Quality of Life Outcomes. 10 (62).

[17] Susilawati. S., Djuharnoko. P., Syaefullah. A., Kartini Sari. D. (2013). Caries and Quality of Life - Evidence of Impacts from Indonesia. Presentation on 7th asian conference oforal health promotion for school children. Bali.
[18] Mofidi. M., Zeldin. LP., and Rozier. RG. (2009). Oral Health of Early Head Start Children: A Qualitative Study of Staff. Parents. and Pregnant Women. American Journal of Public Health. 99(2):245-251.

[19] Jokovic. A., Locker. D., Tompson. B., and Guyatt. G. (2004). Questionnaire for measuring oral health-related quality of life in eight-to ten year- old children. Pediatr Dent. 26: 512-518.

[20] Moynihan. P., and Petersen. PE. (2004). Diet. nutrition and the prevention of dental diseases. Public Health Nutrition. 7(1A): 201-22.

[21] Low. W., Tan. S., and Schwartz. S. (1999). The effect of severe caries on the quality of life in young children. Pediatric Dentistry. 21 (6): 325-326.

[22] Feitosa. S., Colares. V., and Pinkham. J. (2005). The psychosocial effects of severe caries in 4-year-old children in Recife. Pernambuco. Brazil. Cad Saude Publica. 21: 1550 1556.

[23] Bramantoro. T., Hapsoro. A., Roesanto. H., Harumi. RS., Berniyanti. T., Hariyani. N., dan Lydia. M. (2013). Impacts of daily activities related dental caries on 4-6 years old children in Pekukuhan Mojosari. Presentation on 7th asian conference oforal health promotion for school children. Bali.

[24] Martins-Junior. PA., Vieira-Ansdrade. RG., Correa-Faria. P., Oliveira-Ferreira. F., Marques. LS., and Ramos-Jorge. ML. (2013). Impact of Early Childhood Caries on the Oral HealthRelated Quality of Life of Preschool Children and Their Parents. Caries Res. 47: 211-218.

[25] Scapini. A., Feldens. CA., Ardenghi. TM., and Kramer. PF. (2013). Malocclusion impacts adolescents' oral health-related quality of life. Angle Orthod. 83: 512-518. 